\title{
New generation of the satellite hydraulic pumps
}

Leszek OSIECKI

DOI: 10.30464/jmee.2019.3.4.309

Cite this article as:

Osiecki L. New generation of the satellite hydraulic pumps. Journal of Mechanical and Energy Engineering, Vol. 3(43), No. 4, 2019, pp. 309-314.

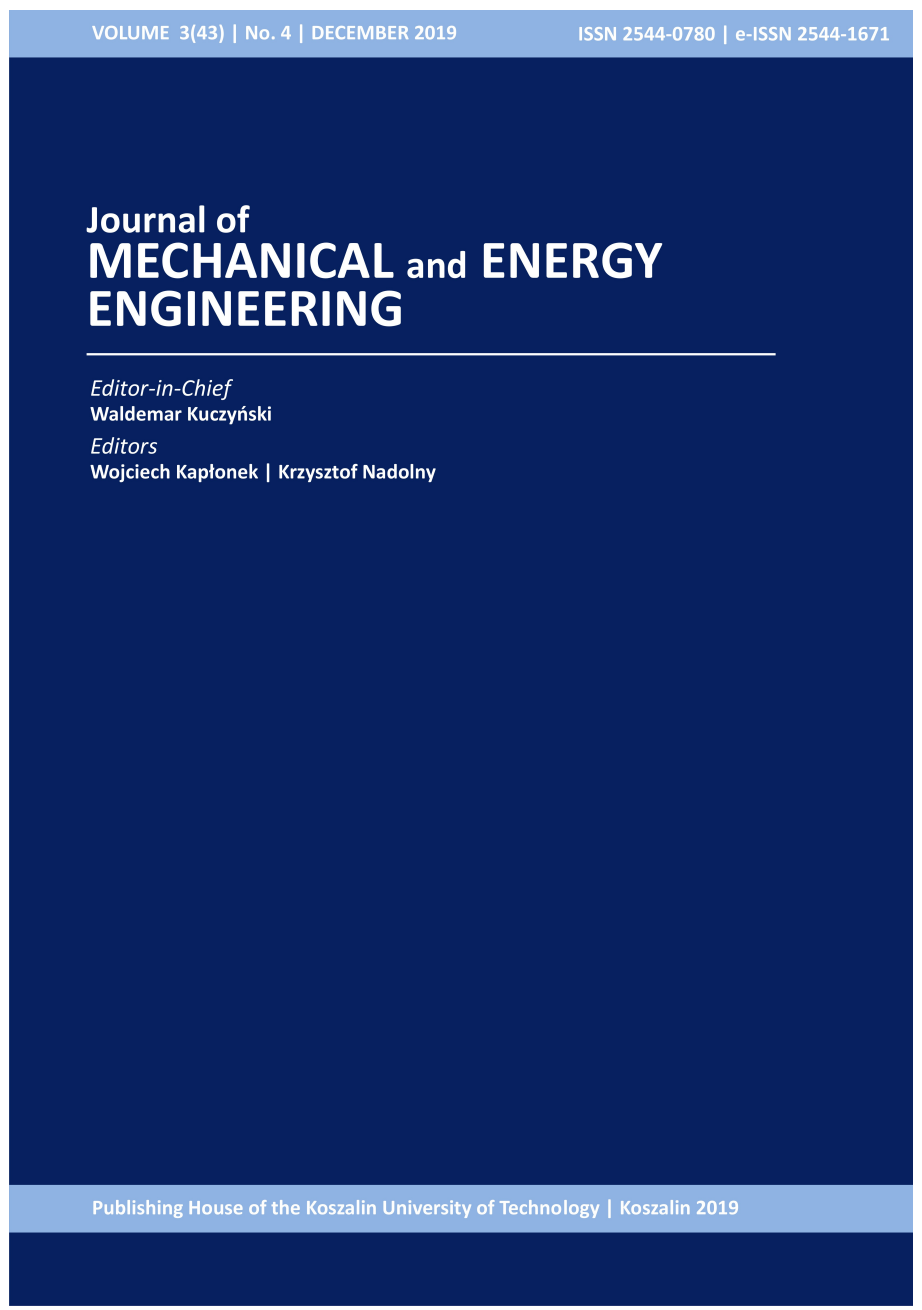

\section{Journal of Mechanical and Energy Engineering}

Website: jmee.tu.koszalin.pl

ISSN (Print): 2544-0780

ISSN (Online): 2544-1671

Volume: $3(43)$

Number: 4

Year: 2019

Pages: 309-314

Article Info:

Received 10 December 2019

Accepted 20 January 2020

\section{Open Access}

This article is distributed under the terms of the Creative Commons Attribution 4.0 (CC BY 4.0) International License (http://creativecommons.org/licenses/by/4.0/), which permits unrestricted use, distribution, and reproduction in any medium, provided you give appropriate credit to the original author(s) and the source, provide a link to the Creative Commons license, and indicate if changes were made. 


\title{
NEW GENERATION OF THE SATELLITE HYDRAULIC PUMPS
}

\author{
Leszek OSIECKI ${ }^{1 *}$ \\ ${ }^{1 *}$ Faculty of Mechanical Engineering, Department of Mechanics and Mechatronics, Gdańsk University \\ of Technology, G. Narutowicza 11/12, 80-233 Gdańsk, Poland, e-mail: losiecki@pg.edu.pl
}

(Received 10 December 2019, Accepted 20 January 2020)

\begin{abstract}
Hydraulic satellite machines are known and produced in many versions, recognizable by the number of humps on their inner rotor and external gear, and therefore by the number of cooperating gears (satellites). All known shapes were however designed on the base of preliminary assumption that rotor's and external gear's pitch lines are formed by merging arcs, tangent to each other in the. This assumption makes calculations easier, but the curvature radius of the pitch lines changes instantly in their merging points. Tests made in the Department of Hydraulics and Pneumatics of the Gdańsk University of Technology proved that satellite motors may work also as a pump. All known shapes were however designed for motor work - mainly for low-speed, high-torque motors. Sudden changes of the pitch line's curvature strongly affect velocity and acceleration of pump's moving parts and forces between them. Because of that, in the pump mode fast wear of teeth in the points of small curvature radius is visible. The obvious effect is reduced durability and high noise emission. To eliminate all those problems the new mechanism, designed for the pump is necessary. The author worked out the new method of calculating satellite mechanism's shape. Instead of merged arcs this method allows to form pitch line as a smooth shape with constantly variable curvature (no rapid changes in any point). Such a mechanism with two-humped rotor, four-humped external gear and six satellites was designed with the use of the new method. Curvature radii of all cooperating elements are relatively high. The proposed shape reduces rapid changes of velocity and forces between pump's elements. It should result in more durable hydraulic satellite pump.
\end{abstract}

Keywords: satellite pump, gear mechanism, pitch line

\section{INTRODUCTION}

Hydraulic satellite motors were first time introduced almost half a century ago, and different versions of those motors are now produced by many companies. The satellite mechanism shown in Fig. 1 consists of a non-circular gear with external teeth (rotor), non-circular external gear with internal teeth, and circular gears (satellites) between them. Gear modulus of the produced motors ranges from $0,4 \mathrm{~mm}$ (high speed motors, displacement $5-10 \mathrm{~cm}^{3} / \mathrm{rev}$ ) to $4 \mathrm{~mm}$ (high torque motors, displacement up to $6.3 \mathrm{dm}^{3} / \mathrm{rev}$ ). High speed motors, called SM motors emerged on the market thanks to research conducted by the team of Hydraulics and Pneumatics of Gdansk University of Technology in cooperation with Stosowanie Maszyn company. Laboratory tests of the SM motors proved their ability to reach $1800 \mathrm{rpm}$ with working pressure up to $25 \mathrm{MPa}$. It means that power density of those motors is very high and may exceed $4 \mathrm{~kW} / \mathrm{kg}$.

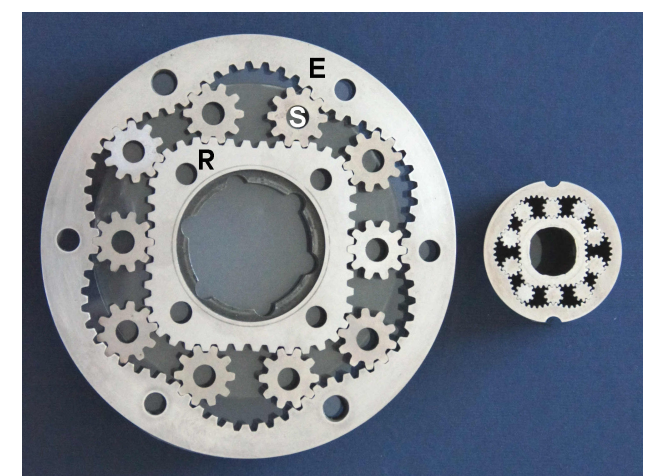

Fig. 1. Examples of $4 / 6$ satellite mechanisms: $\mathrm{R}$ - rotor, E - external gear, $\mathrm{S}$ - satellite 
One of the main advantages of SM satellite motors is also their ability to work with different fluids like: mineral and vegetable oil, non-flammable fluids and even the pure water [1,2].Thanks to this ability and low weight satellite motors have found wide use: especially in mining and marine industries.

\section{DESIGN AND PERFORMANCE OF SATELLITE PUMPS}

Parameters of the SM motors encouraged to test their ability to work as a pump. The new PSM pump (Fig. 2) was designed on the basis of the SM motor and subjected to tests in laboratory. Tests results confirmed it's ability to pump different fluids (i.e. mineral oil, water, HFAE emulsion) within the wide range of working parameters.

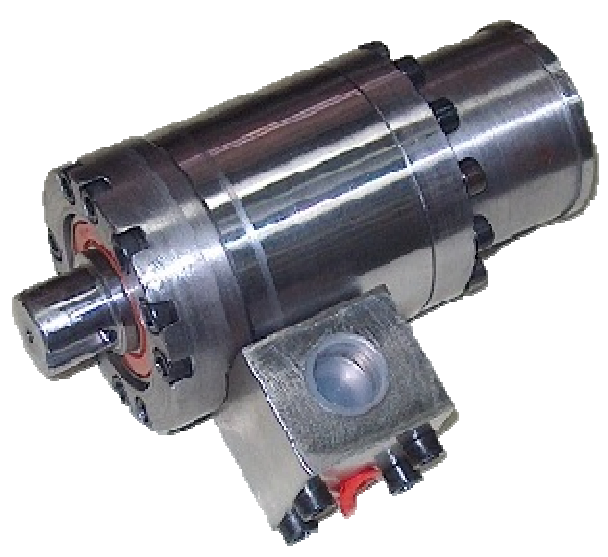

Fig. 2. PSM satellite pump [3]

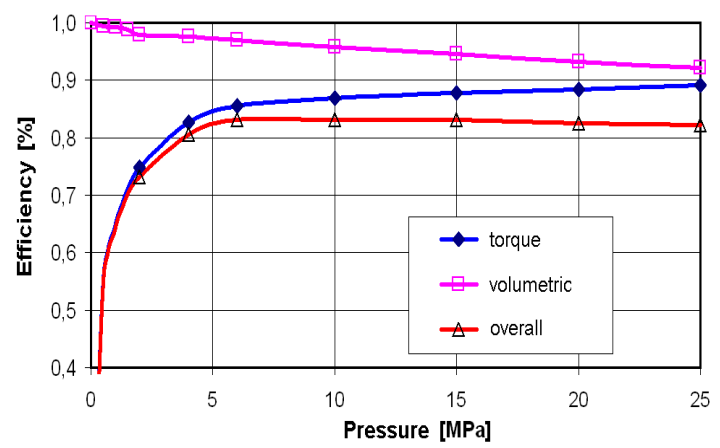

Fig. 3. PSM pump performance, speed - $1000 \mathrm{rpm}$, fluid mineral oil HG 46 [5]

Efficiency of the PSM prototypes reaches the same level as efficiency of modern hydraulic vane or gerotor pumps produced by leading manufacturers (Fig. 3 and 4) [5], after improvement of it's compensation unit the new pump may exceed $90 \%$ and reach the efficiency level of the gear pumps.

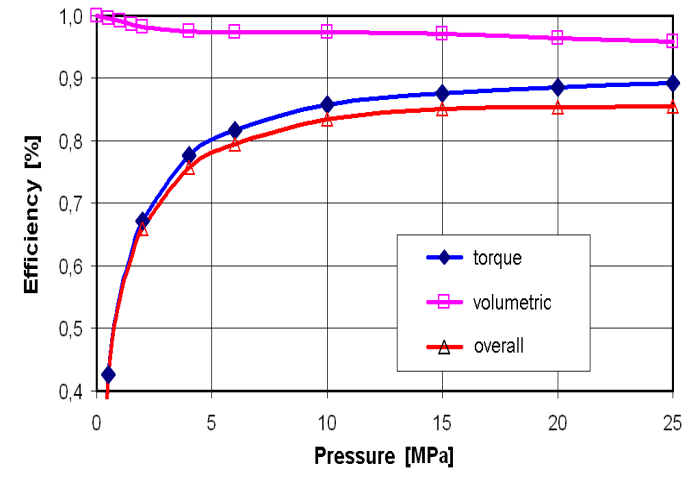

Fig. 4. PSM pump performance, speed $-1500 \mathrm{rpm}$, fluid HFAE emulsion [5]

\section{TECHNICAL PROBLEMS}

Laboratory tests of the PSM pump prototypes confirmed ability of the satellite mechanism to work as a pump and to reach parameters like rotational speed and pressure required in modern hydraulic drive systems, but revealed also some disadvantages of the new concept.

First problem is a little radius of rotor's curvature near it's humps. It causes harmful conditions of cooperation between teeth and their fast wear. This phenomenon mainly affects the strongly curved, convex areas of the rotor marked in Fig. 5a. After a relatively short period of time rotor's teeth in those regions show significant wear (see Fig. 5b [6]).

a)

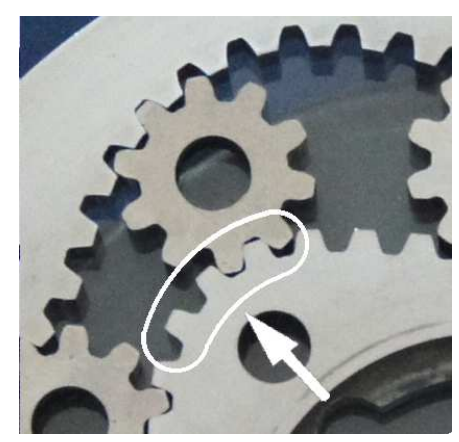

b)

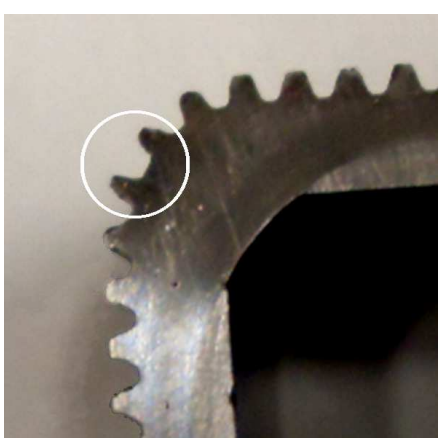

Fig. 5. New mechanism (a) and worn out rotor (b) [6] 
Such a phenomenon significantly reduces the durability of the pump and may lead to it's damage. The shapes of the presently produced satellite mechanisms were primarily designed for high torque hydraulic motors. The gear modulus in those machines ranged from $1,5 \mathrm{~mm}$ up to $4 \mathrm{~mm}$, and motor's speed was usually less than $250 \mathrm{rpm}$. Under those conditions teeth wear was negligible. On the contrary, pump's rotational speed is usually high - $1500 \mathrm{rpm}$ or more, while teeth modulus ranges from 0.4 to $1 \mathrm{~mm}$. This makes the teeth wear problem much more important.

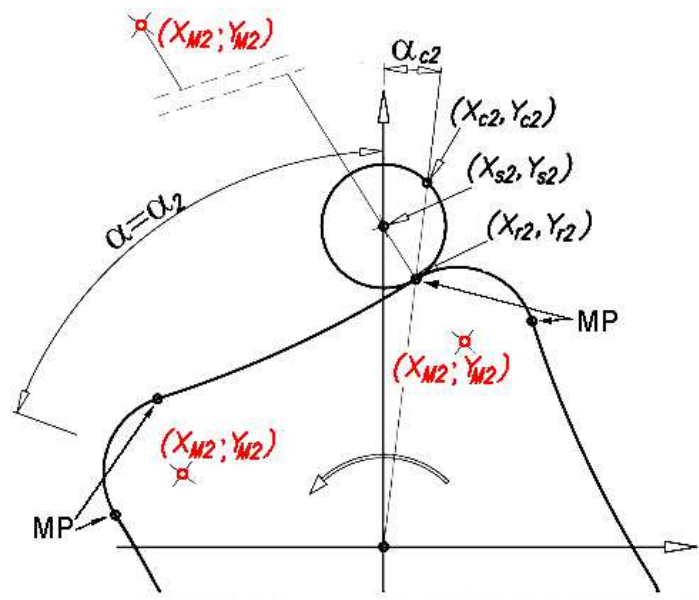

Fig. 6. Pitch lines of the rotor and satellite in present $4 / 6$ mechanism. MP - merging points [4]

The second problem stems from the design methods used for determining the shapes of both the rotor and external gear. In all present versions the pitch lines are formed from arcs merging in certain points (marked as MP in Fig. 6) and tangent to each other in the MP. Points shown in red mark positions of the centers of curvature of successive arcs. Such a shape of the pitch line makes the mechanism design process much easier, but badly affects the performance of high speed pumps or motors.

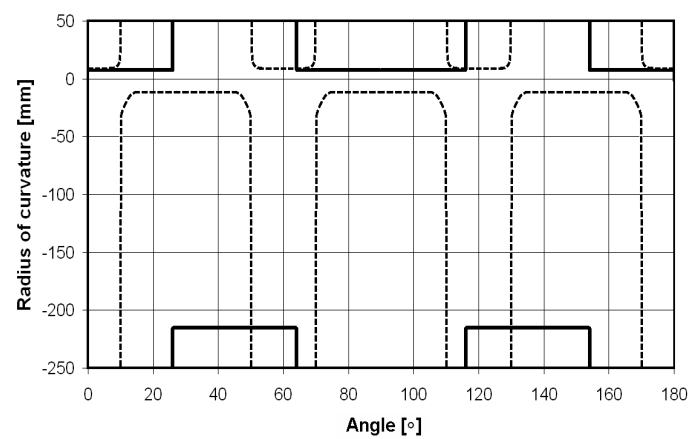

Fig. 7. Changes of curvature radii in present $4 / 6$ mechanism: solid line - rotor, dashed line - external gear
The pitch line in every MP changes rapidly it's radius of curvature (both value and sign - see Fig. 7). Positive values of the radius mean convex shape of the pitch line, negative - concave shape. For the commonly used present $4 / 6$ mechanism with $0.75 \mathrm{~mm}$ teeth modulus the most important minimal positive value of the curvature radius of the rotor's pitch line equals $7.5 \mathrm{~mm}$. Corresponding value for the external gear is $7.65 \mathrm{~mm}$. Cooperating satellites have constant curvature radii: $+3.75 \mathrm{~mm}$. Such a shape causes also rapid changes of speed and acceleration of the cooperating satellite in the moment when it crosses the merging point (see Fig. 8 and 9) and thus big forces exerted on all parts of the mechanism.

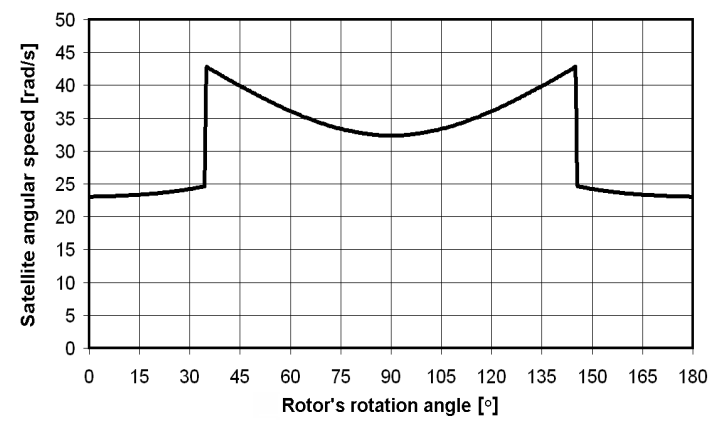

Fig. 8. Changes of the satellite's rotational speed in present $4 / 6$ mechanism. Rotor's speed $\omega=10 \mathrm{rad} / \mathrm{s}$ [4]

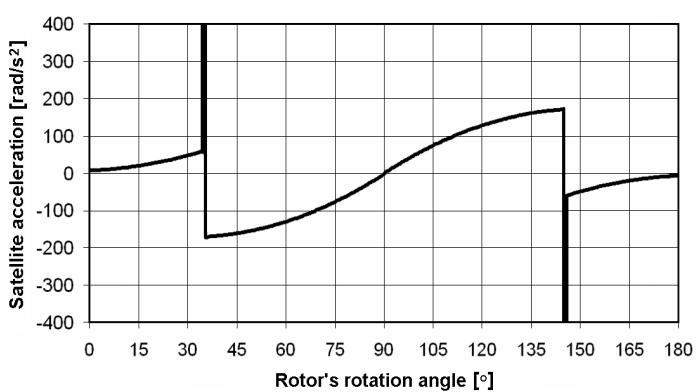

Fig. 9. Changes of the satellite's acceleration in present $4 / 6$ mechanism. Rotor's speed $\omega=10 \mathrm{rad} / \mathrm{s}$ [4]

\section{THE NEW MECHANISM}

Each satellite gear mechanism to work properly must fulfill three basic conditions [7]:

- contacting pitch lines must roll over each other with no slip between them,

- pitch lines must have cyclic shape with no sharp edges (if pitch lines are formed as a set of merged arcs, those arcs must be tangent to respective one in their merging points),

- lengths of all pitch lines must be in rational proportion to each other (teeth numbers must be integral).

Calculation methods for existing satellite mechanisms are described in $[4,7]$, but those methods are 
applicable only in case of pitch lines formed as a set of arcs. To solve mentioned above problems with rapid changes of curvature and fast teeth wear the new shape calculation method is necessary. The pitch lines for rotor and external gear have to be based on the single mathematic formula describing the pitch line's shape instead of set of tangent arcs. Such a line must also meet two additional criteria:

- constantly variable radius of curvature,

- possibly high value of the minimal curvature radius.

All three previously mentioned conditions are, of course, still obligatory.

\subsection{The new layout of the mechanism}

On the contrary to all present shapes the new mechanism was designed to work as a pump, not as a motor. Theoretically, many variations of the satellite mechanism are possible [9]. They vary in number of humps on both rotor and external gear (Fig. 10). The number of satellites in all cases equals to the sum of the rotor and external gear hump numbers. As an example, the most popular version of the satellite mechanism, marked as 4/6 mechanism, consists of four-humped rotor, six-humped external gear and ten satellites (see Fig. 1).

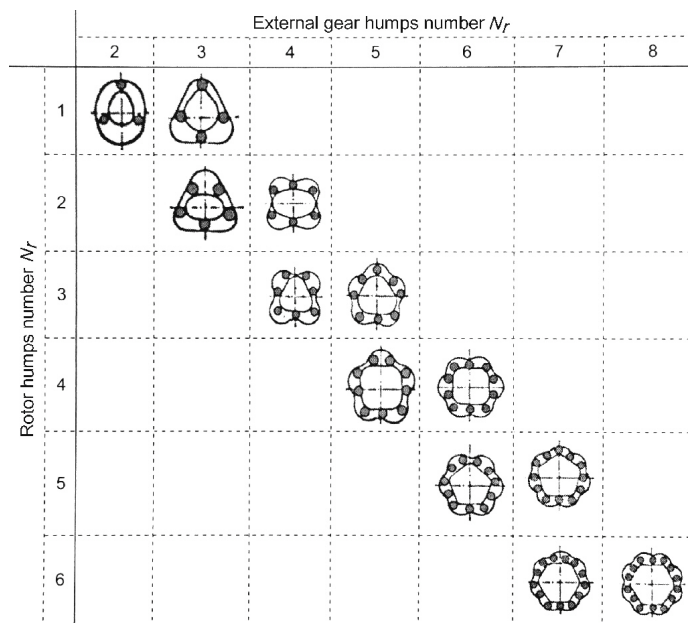

Fig. 10. Some possible layouts of the satellite gear mechanism [9]

From the set of theoretically possible layouts the $2 / 4$ mechanism was chosen for the new pump. The rotor in such a mechanism has only two humps, while external gear has four of them. Both gears cooperate with six satellites (Fig. 10 and 11). The proposed shape reaches high displacement-to-dimensions ratio and thanks to smaller number of satellites reduces the total number of working cycles for every revolution of the rotor.

\subsection{Calculation of the new shape}

To meet the criteria mentioned in chapter 4 the completely new method of shape calculation was required. What's more, the analytic method of shape calculation cannot be used. Rotor's shape in the 2/4 mechanism is based on the ellipse equation. Precise calculation of the ellipse length is known in mathematics as one of the insolvable problems. On the other hand, precise length value is necessary to establish the number of teeth, otherwise the satellite mechanism cannot work properly. The only solution for that case was to apply numerical calculations with dense partition. Such a software was designed and tested. The results obtained thanks to the new method confirmed the possibility of creating many new versions of the satellite mechanism, all capable of meeting the mentioned above requirements. Some examples of the new mechanism with the respective teeth numbers are shown in Fig. 11. a)

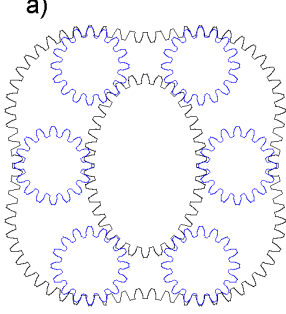

$S=16 \quad R=34 \quad E=68$ b)

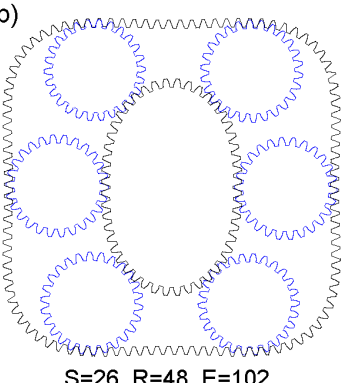

Fig. 11. Examples of the new $2 / 4$ pump mechanism: $\mathrm{S}$ - number of satellite teeth, $\mathrm{R}$ - rotor teeth, E - external gear teeth

\subsection{Properties of the new mechanism}

The new $2 / 4$ mechanism (version a) in Fig. 11) was subjected to the same analysis as the $4 / 6$ present one. In both cases the same values of the teeth modulus and rotor's angular speed were assumed $0.75 \mathrm{~mm}$ and $10 \mathrm{rad} / \mathrm{s}$ respectively.

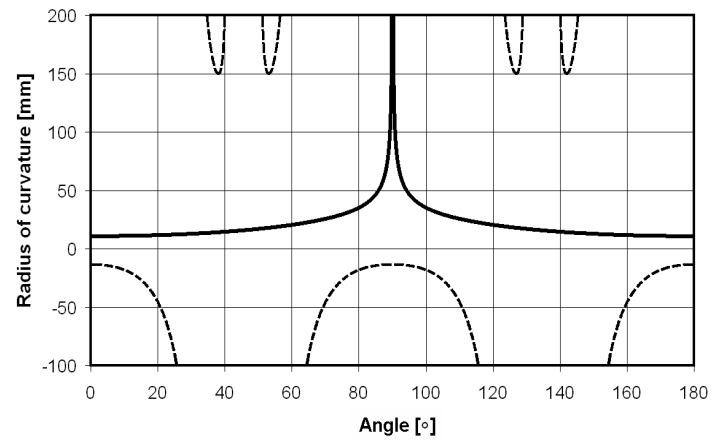

Fig. 12. Changes of curvature radii in new 2/4 mechanism: solid line - rotor, dashed line - external gear

Figure 12 shows changes of the curvature radii of both rotor and external gear. The most important minimal positive values for the convex parts of the pitch lines equal: $10.63 \mathrm{~mm}$ for the rotor and $150 \mathrm{~mm}$ 
for the external gear. The satellite's pitch line radius is $6.0 \mathrm{~mm}$. What's more, curvature radii of the new mechanism don't change so rapidly as in the present one (compare Fig. 7).

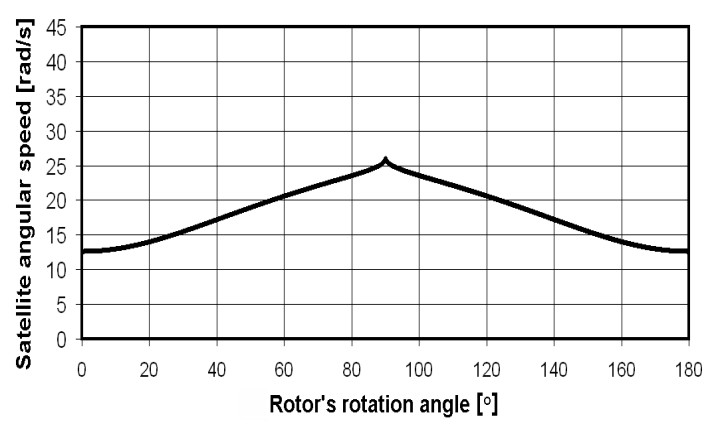

Fig. 13. Changes of the satellite's rotational speed in new $2 / 4$ mechanism. Rotor's speed $\omega=10 \mathrm{rad} / \mathrm{s}$ [10]

The satellite angular speed values dropped from $23-43 \mathrm{rad} / \mathrm{s}$ range to $13-26 \mathrm{rad} / \mathrm{s}$. What's important, there are no sudden speed changes, similar to those shown in Fig. 8.

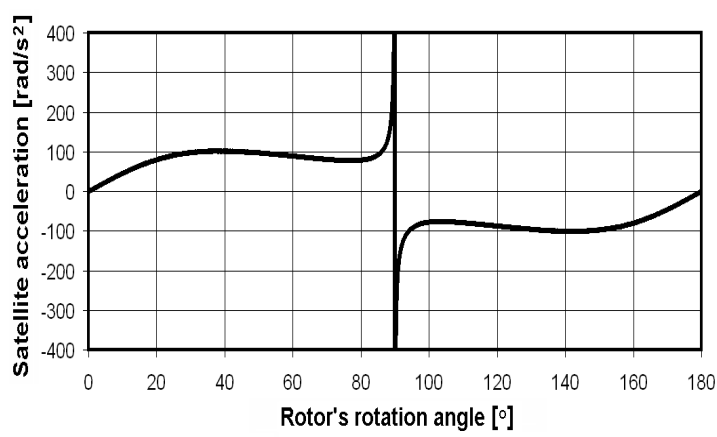

Fig. 14. Changes of the satellite's acceleration in new $2 / 4$ mechanism. Rotor's speed $\omega=10 \mathrm{rad} / \mathrm{s}$ [10]

Thanks to reduction of speed changes values of angular acceleration of the satellite are also significantly smaller. For more than $90 \%$ of the working cycle acceleration changes slowly, and doesn't exceed the range of $\pm 105 \mathrm{rad} / \mathrm{s}^{2}$. For every full revolution of the rotor two peak values of the acceleration occur, both reaching $\pm 1600 \mathrm{rad} / \mathrm{s}^{2}$. In the present $4 / 6$ mechanism the typical acceleration range is $\pm 175 \mathrm{rad} / \mathrm{s}^{2}$, while number of peaks rises to four per each revolution and their value exceeds $\pm 20000 \mathrm{rad} / \mathrm{s}^{2}$ (Fig. 9). Similar results were obtained for the second version of the new pump shown as b) in Fig. 11 .

\section{REVERSE KINEMATICS OF THE SATELLITE MACHINE}

It is possible to build satellite pumps and motors in two versions. In the first one, machine's kinematics is typical: internal gear rotates while external gear remains fixed. The second version - reverse kinematics - applies rotating external gear and fixed internal gear [11, 12]. The complex satellite's motion in both machines remains similar.

The reverse kinematics has many advantages: commutation windows are much larger, reducing pump's internal pressure drop and improving it's efficiency. Thanks to high power density such a pump can be installed inside the typical electric motor, allowing to create compact and effective pumping unit (Fig. 15) [13]. The new $2 / 4$ mechanism in the reverse kinematics version perfectly matches such a design.

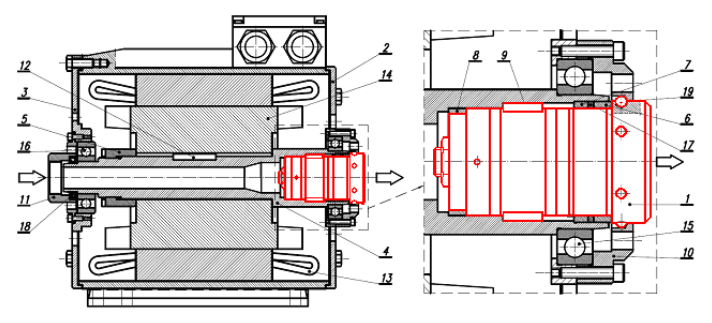

Fig. 15. Pumping unit with the reverse kinematics satellite pump (marked in red) [13]

The weight and length of the whole pumping unit is smaller than weight and length of the electric motor itself . For safety reasons it is also important that there are no external rotating parts.

\section{SUMMARY}

The preliminary analysis confirmed possibility of reduction of harmful phenomena occurring in the mechanism of satellite pump. Thanks to higher curvature radii of all cooperating elements, smooth pitch lines and smaller number of working cycles per each revolution reduction of the teeth wear is likely. The new calculation method is capable of creating different shapes founded on different mathematic formulas, all of them meet the required criteria.

To create fully operational pump the next step of research is necessary. Both rotor and external gear shapes need optimization. The target is reduction of the pump's flow ripple and noise emission with simultaneous maximizing of its displacement [8]. Similar modifications may be also applied in highspeed satellite motors, where the fast teeth wear may also occur.

\section{References}

1. Balawender A., Śliwiński P. et al.: R\&D of small displacement hydraulic satellite motors and pumps supplied with water, emulsion and oil. Report from R\&D project nr R0300103. Gdańsk University of Technology, 2010, (in Polish).

2. Patrosz P.: New possibilities of generating satellite mechanism shapes. International conference "Hydrostatic and Pneumatic Drive and Control - 2012", Wrocław, Poland, 2012, (in Polish). 
3. Sliwiński P.: New satellite pumps. Key Engineering Materials: Fundamentals of Machine Design. Vol. 490, 2012

4. Śliwinski P.: Satellite displacement machines. Basis of design and analysis of power loss. Monograph. Gdańsk University of Technology, 2016, (in Polish).

5. Sliwiński P.: The influence of water and mineral oil on mechanical losses in the displacement pump for offshore and marine applications. Polish Maritime Research, Special Issue, Vol 25, 2018.

6. Patrosz P., Śliwiński P.: Compact satellite hydraulic unit. Machines, Technologies, Materials. Scientific Technical Union of Mechanical Engineering. Sofia, Bulgaria, 2014.

7. Kujawski M.: Satellite mechanisms with non-circular gears. Basis of design and manufacturing. Monograph. Poznań University of Technology, 1992, (in Polish).

8. Kujawski M.: Kinetostatic analysis of the satellite hydraulic motors with non-circular gears. Maszyny Górnicze nr 5/59, Special Issue "Cylinder '96", Gliwice 1996, (in Polish).

9. Sieniawski D.: Flow ripple of the satellite machines Thesis. Gdańsk University of Technology, 1985, (in Polish).

10. Osiecki L.: Development of the satellite pump design Napędy i Sterowanie, Vol 12(236), 2018 (in Polish).

11. Śliwiński P., Osiecki L.: Pumping Unit. Patent PL 216999.

12. Śliwiński P., Osiecki L., Patrosz P.: Fluid displacement machine with reverse kinematics satellite mechanism. Patent PL 226516.

13. Śliwiński P., Osiecki L., Patrosz P.: Satellite pumping units. In: From Finite Elements Method to Mechatronics. Gdańsk University of Technology, 2017, (in Polish).

\section{Biographical note}

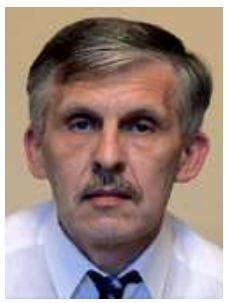

Leszek Osiecki received his M.Sc degree in Mechanics and Machine Design from Gdańsk University of Technology, Faculty of Machine Design, in 1981. After 10 years of industrial practice (mainly in Ship Machinery Works "Hydroster" as a designer of hydraulic pumps and cylinders) he started his research work in Gdańsk University of Technology, Faculty of Mechanical Engineering, where he still works as an associate professor. In 1999 he received his PhD from Poznań University of Technology and in 2007 DSc from Gdańsk UT. His scientific interests focus on design and testing of hydraulic pumps, high pressure systems and satellite mechanisms. 